\title{
A new genus and species of rhinatrematid caecilian (Amphibia: Gymnophiona: Rhinatrematidae) from Ecuador
}

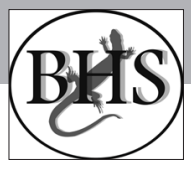

\author{
Mark Wilkinson ${ }^{1}$, Robert P. Reynolds ${ }^{2}$ \& Jeremy F. Jacobs ${ }^{3}$ \\ ${ }^{1}$ Life Sciences, The Natural History Museum, London SW7 5BD, UK \\ 2031 Isles of Saint Marys Way, Saint Marys, Georgia 31558 U.S.A \\ ${ }^{3}$ Department of Vertebrate Zoology, National Museum of Natural History, Smithsonian Institution, Washington D.C., N.W., 20560
}

\begin{abstract}
A new genus and species of rhinatrematid caecilian, Amazops amazops gen. et sp. nov., is described based on a single specimen from Orellana, Ecuador collected in 1990. Among other features the new taxon differs from all other rhinatrematid caecilians in having less than four annular grooves interrupted in the region of the vent and in the squamosal contributing to the bony margin of the orbit. A consideration of its distinctive morphology suggests that it is plausible that the new taxon is the sister taxon of all other rhinatrematid caecilians. That the genus is known from a single specimen, and that this is the first new rhinatrematid species from the Andes described for more than 50 years, highlights the poor sampling (collecting) of rhinatrematid caecilians and limited knowledge of their diversity.
\end{abstract}

Keywords: Andes, biodiversity, computed tomography, morphology, South America, systematics, taxonomy

\section{INTRODUCTION}

$\mathrm{T}$ he caecilian family Rhinatrematidae was established by Nussbaum (1977) to receive the neotropical caecilian species that Taylor (1968) had assigned to his family Ichthyophiidae, thereby restricting the latter to Asia. Rhinatrematids are the only caecilians with open skull roofs (zygokrotaphy) associated with primary jaw adductor muscles extending through the upper temporal fenestrae (Nussbaum, 1977), and that lack an elongate truncus arteriosus (Wilkinson, 1996). They are relatively short and stout bodied caecilians that retain short tails, have many annuli and annular scales, and, as far as is known, are oviparous with an aquatic larval stage. Phylogenetic analyses of both morphological and molecular data agree that the Rhinatrematidae represents one side of the basal divergence within the extant caecilians and is thus the sister group of all other living caecilians (e.g., Wilkinson \& Nussbaum, 1996; San Mauro et al., 2014).

In 1990, two of us (RPR \& JFJ) made a brief unscheduled stop on route from Quito to Loreto in the Amazonian versant of Ecuador. Beneath a rock or rocks on a dirt road, with a very muddy, soft, red substrate and much seeping water they found a small, unicoloured caecilian. Based on the position of the tentacle and length of the tail, among other features, this caecilian was readily identifiable as a rhinatrematid and tentatively identified as a species of Epicrionops Boulenger, 1883. However, based on their initial investigations its specific status was less clear. Four of the eight species of Epicrionops recognised at that time lacked a stripe but these were reported as having rather more or substantially fewer annular grooves than the new specimen, suggesting either that the ranges of annular grooves of the described species, many of which were known only from very small samples, were underestimated or that the new specimen represented an undescribed species. Subsequent investigation by the senior author and anatomical comparisons with type specimens of all other species of Epicrionops and of three of the five currently recognised species of the other rhinatrematid genus Rhinatrema Dumeril \& Bibron, 1843, confirms the specimen belongs to a previously undescribed rhinatrematid species and reveals that its morphology is sufficiently distinctive to warrant the establishment of a new genus to receive it.

\section{MATERIAL AND METHODS}

Upon collection the specimen was immediately closed inside a plastic bag with moist ferns, kept cool and euthanised within 12 hours of capture by submerging in a solution of hydrous chlorobutanol (Chloretone), positioned and fixed in $10 \%$ buffered formalin, and subsequently washed and transferred to $70 \%$ ethanol for long term storage.

Cranial and caudal osteology and scales were visualised with high-resolution x-ray computed 
tomography (the results referred to here as CT scans) using a Metris X-Tek HMX ST 225 System with a molybdenum target set at $180 \mathrm{kV}$ and $200 \mu \mathrm{A}$. Scan data were collected over 3142 projections (two frames per second) in $360^{\circ}$, with reconstructed voxel size of $8 \& 10 \mu \mathrm{m}$ respectively, and rendered as a three-dimensional volume using VGStudio MAX v2.1 (Volume Graphics, http://www. volumegraphics.com) which was used to generate images. Comparisons were made with information on cranial morphology including published (Nussbaum, 1977; Reiss, 1996; Gower et al., 2010) and unpublished observations, illustrations and CT scans of all other rhinatrematid species with the exceptions of the recently described Rhinatrema gilbertogili Maciel, Sampaio, Hoogmoed, and Schneider, 2018 and Rhinatrema uaiuai Maciel, Sampaio, Hoogmoed, and Schneider, 2018. CT scan data are available from the senior author upon reasonable request.

Total lengths and circumferences were measured to the nearest millimetre $(\mathrm{mm})$ with a ruler, the latter by wrapping a piece of string around the body. Other measurements were made to the nearest $0.1 \mathrm{~mm}$ with dial callipers. Observations and direct counts of teeth were facilitated by the Nussbaum technique, i.e., using a directed stream of compressed air to temporarily dry and shrink the gingivae (Wilkinson et al., 2013). Tooth counts were also made from CT scans. In both cases, tooth counts include empty sockets and must be considered estimates rather than definitive. Sex was determined by direct examination of gonads via a midventral incision in the body wall. Number of vertebrae was determined by X-radiography, using a Matchlett Solus Schall, beryllium window, copper target tube exposing Kodak MX100 film for 25 seconds at settings of 25 kilovolts and 10 milliamps. Annular scales were sought by opening selected scale pockets by running a needle along the corresponding annular groove. Posterior scales were also visualised through CT scanning.

Following common usage we refer to an area around the vent that is differentiated in colour or structure from the adjacent skin as the disc and the fleshy margins of the upper and lower jaws that form the edges of the mouth as lips. Following Wilkinson et al. (2014; 2017) we use first and last to denote the anteriormost and posteriormost units of serial homologues, and front and back (and behind) to denote anterior or posterior (to) respectively. Where helpful, observations were made with the assistance of a dissecting microscope.

\section{RESULTS}

\section{Amazops gen. nov.}

\{urn:Isid:zoobank.org:act:D9F1C39D-4B47-46CF-AB9D51896D4C619C\}

Diagnosis. Rhinatrematid caecilians with the squamosal contributing to the margin of the orbit.

Content: A single species Amazops amazops, sp. nov., the type by monotypy and by designation.

Etymology: The name is a portmanteau word combining reference to the Amazonian provenance of the type and only known species and the distinctive topological relationships of its eye and orbit, particularly the contribution of the squamosal to the bony margin of the orbit, which is unknown in any other rhinatrematid. As mandated by the code, gender is masculine.

Remarks: Three other features of the only known specimen of this genus are distinctive, known in no other rhinatrematids and might be diagnostic for the genus: lack of contact between the quadrate and maxillopalatine, contact between the squamosal and frontal and the small number of annular grooves that are interrupted by the vent.

\section{Amazops amazops sp. nov.}

\{urn:Isid:zoobank.org:act:55BF6D3F-2B30-4EB2BEFE-917532513286\}

(Figs. 1-5)

Holotype. United States National Museum of Natural History, Smithsonian Institution (USNM) 320729, a female collected by Jeremy F. Jacobs and Robert P. Reynolds from Finca Virgen La Dolores, at km 57 sign on Hollin-Loreto Road (E20), Orellana, Ecuador, c. 0 degrees $43^{\prime}$ 50" South and 77 degrees 30' 25" West, and c. 1000m above sea level, 16th August 1990. According to the map available at the time (titled "Republica Del Ecuador" and "Compilado Por El Instituto Geografico Militar," Escala 1:1'000.000, published by the Ministerio De Relaciones Exteriores in Quito, Ecuador, dated 9 November 1981), the type locality, which was in the Province of Napo (Orellana having been established in 1998), is in the vicinity of the "Cordillera Galeras" and featured hillsides through cutover forest with abundant epiphytes. The "Hollin-Loreto road" was not on the map but was provided by the driver, Ramiro Donoso. This is shown as E20 on modern maps.

Diagnosis. As for the genus.

Identification. Based on external morphology alone, the new species is readily distinguished from all other rhinatrematids by having very few (less than four) annular grooves interrupted by the vent. Further, the combination of low number of annular grooves $(<275)$ and its uniform colour distinguishes it from all other rhinatrematids except E. colombianus (Rendahl \& Vestergren, 1938), the only known specimen of which has even fewer annular grooves $(<225)$.

Description of holotype. Good condition, an c. 20 $\mathrm{mm}$ midventral longitudinal incision c. $30 \mathrm{~mm}$ anterior to tail tip, some open scale pockets, mouth preserved open. Total length $173 \mathrm{~mm}$. Body subcylindrical, mostly somewhat dorsoventrally compressed (at midbody: width $7.3 \mathrm{~mm}$, depth $4.5 \mathrm{~mm}$, circumference $20 \mathrm{~mm}$ ), less so posteriorly, not compressed (width $4.0 \mathrm{~mm}$, depth $4.0 \mathrm{~mm}$ ) at level of vent, fairly uniform, narrowing slightly anteriorly and more notably posteriorly. Tail moderately long, $7.6 \mathrm{~mm}$, slightly laterally compressed, $3.0 \mathrm{~mm}$ wide and $3.5 \mathrm{~mm}$ deep c. half way between vent and tail tip, tapering more strongly in dorsal than in lateral view, tip much more broadly blunt in lateral than in dorsal view, dorsal and ventral margins symmetrical in lateral view, ventral surface not flat.

Head $7.0 \mathrm{~mm}$ from snout tip to corner of mouth, 9.0 $\mathrm{mm}$ from snout tip to first nuchal groove behind corner 


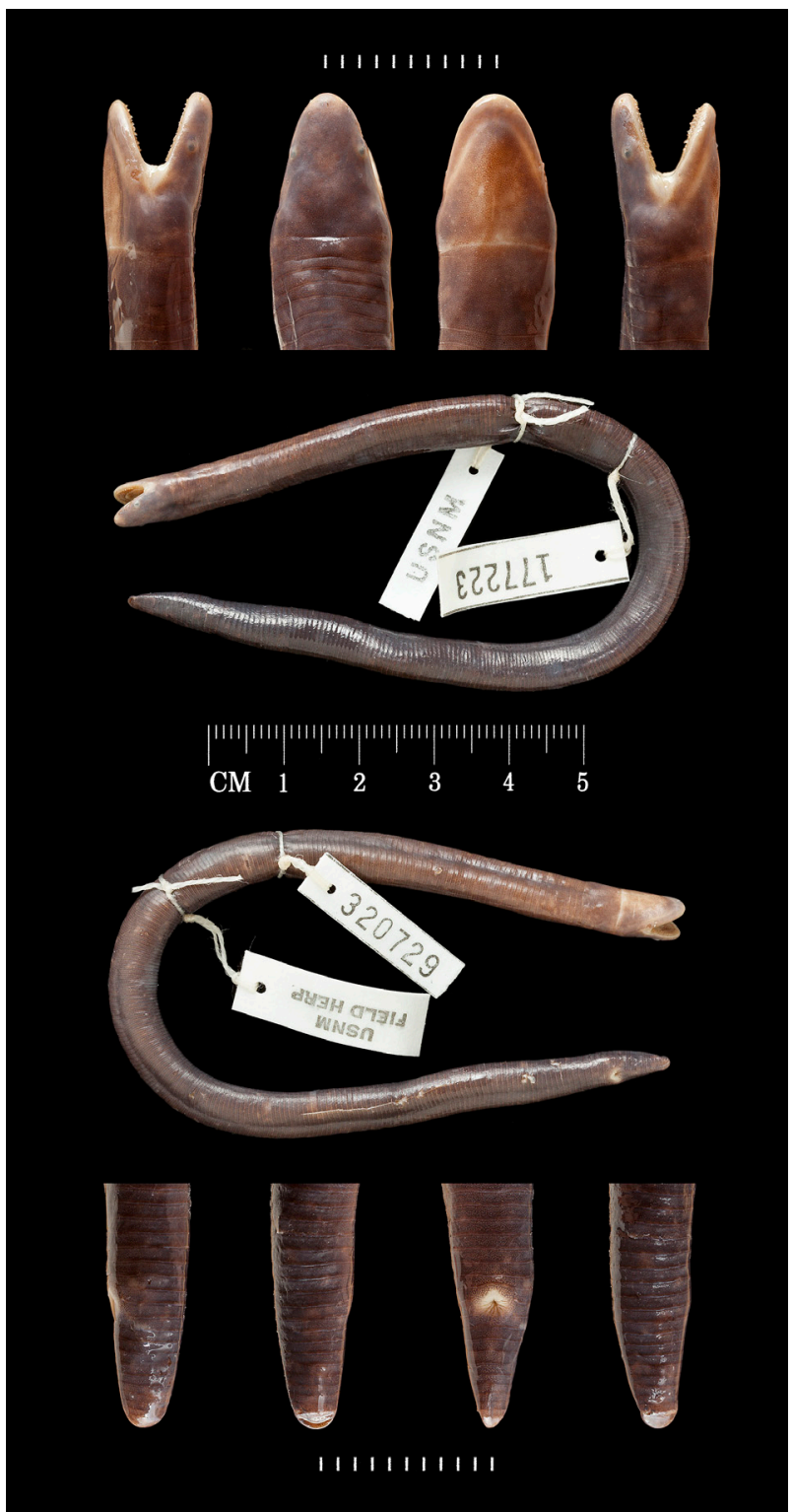

Figure 1. USNM 320729, holotype of Amazops amazops sp. nov. with head end (top), whole body (middle) and tail end (bottom). Scale bar gradations in $\mathrm{mm}$. Photo by Harry Taylor (Natural History Museum, London).

of mouth, in dorsal view slightly more V- than U-shaped, dorsoventrally compressed, as wide $(6.1 \mathrm{~mm})$ and deep $(4.9 \mathrm{~mm})$ as adjacent nuchal region posteriorly, narrowing gently anteriorly up to about a third of the way between eyes and nares in front of the eyes. In ventral view, lower jaws virtually as wide as head, tip more bluntly rounded than snout anteriorly, mouth marginally subterminal (anterior of mouth to snout tip $0.7 \mathrm{~mm}$ ). In lateral view, head tapers very gently anterior to eye level, sharply from level of nares, edges of mouth (lips) fairly straight, slightly downturned at corner of mouth, corner of mouth slightly further from top than from bottom of head, lower jaws robust, almost as deep as upper jaws at eye level.

Circular eyes small (diameter $0.4 \mathrm{~mm}$ ), central grey lens and darker periphery clearly visible through skin, elevated above adjacent skin, equidistant from top of head and lip in lateral view, inset by almost one diameter from outline of head in dorsal view. Tentacular apertures

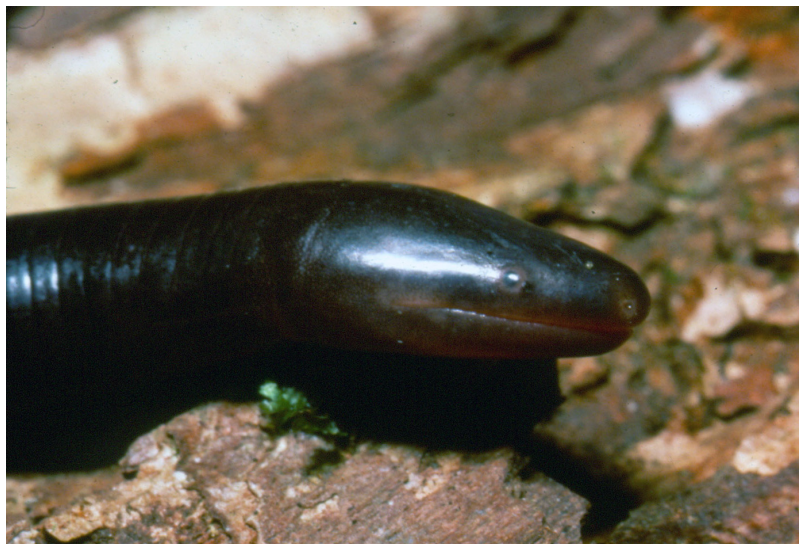

Figure 2. USNM 320729, holotype of Amazops amazops sp. nov. in life. Photo by William W. Lamar.

small $(0.6 \mathrm{~mm})$ almost horizontal arc-like slits, curving ventrally at their ends, extending anteriorly from the middle (i.e., at three o'clock) of the anterior edge of eye, their margins slightly elevated, the tips of the paired tentacular ducts of each side (leading from the tentacle to the vomeronasal organ) visible through the skin adjacent to the anterior end of the tentacular apertures. Nares small $(0.3 \mathrm{~mm})$, subcircular on left, more tear shaped on right, deeper and broader anteriorly, visible dorsally inset about one and a half diameters from outline of head; in lateral view, slightly closer to tip than to top or bottom of snout; slightly closer to lips $(0.7 \mathrm{~mm})$ than are eyes $(0.8$ $\mathrm{mm})$, visible in anterior but not ventral views. Distance between nares $(1.5 \mathrm{~mm})$ half the distance from naris to eye $(3.0 \mathrm{~mm})$.

Teeth pointing posteriorly (at angles of $30^{\circ}$ to $45^{\circ}$ from the jaws), not strongly recurved, bicuspid, anterior and posterior teeth of each series smaller than those in between, none hypertrophied, outer mandibular ("dentary") teeth (36) generally a little larger than opposing premaxillary-maxillary teeth (42) and vomeropalatine teeth (40), inner mandibular ("splenial") teeth (24) a little smaller. Curvature of premaxillarymaxillary tooth series following that of upper lip, vomeropalatine tooth series straighter except anteriorly, extending slightly (about three teeth on each side) beyond the last premaxillary-maxillary teeth, distance between upper series narrowing posteriorly, maximal laterally (about the level of half way between the eye and the naris). Inner mandibular tooth series straightening a little anteromedially, much shorter than the outer mandibular series, about one quarter of the length of the outer mandibular tooth series (about six teeth on each side) posterior to the last inner mandibular teeth.

Based on the CT scan there are nine premaxillary teeth (five right, four left), 33 maxillary teeth (17 right, 16 left) for a total of 42 premaxillary-maxillary teeth, 13 vomerine (six right, seven left) and 26 palatinal teeth (12 right, 14 left, two on each side posterior to the last maxillary teeth) for a total of 39 vomeropalatine teeth, 37 outer mandibular teeth (19 right, 18 left) and 22 symmetrically disposed inner mandibular teeth, with seven (right) and eight (left) outer mandibular teeth behind the level of the last inner mandibular teeth. 


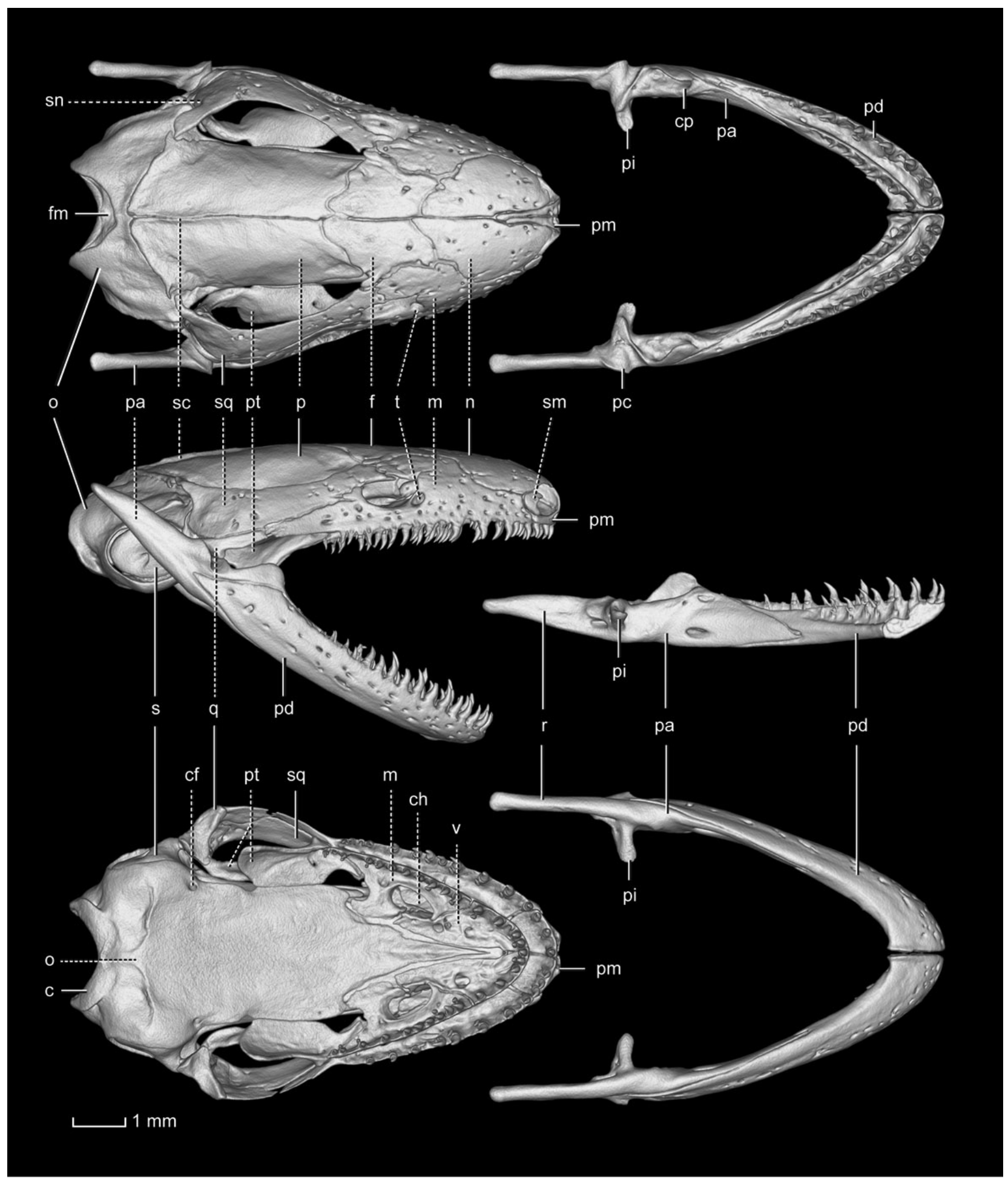

Figure 3. CT scan of skull USNM 320729, holotype of Amazops amazops sp. nov. in dorsal (top), right lateral (middle) and ventral (bottom) views. $c=$ occipital condyle; $c f=$ carotid foramen; $c h=$ choana (internal nostril); $c p=$ canalis primordialis; $f=$ frontal; $\mathrm{fm}$ = foramen magnum; $\mathrm{m}$ = maxillopalatine; $\mathrm{n}=$ nasal; $\mathrm{o}=$ os basale; $\mathrm{p}=$ parietal; $\mathrm{pa}=\mathrm{pseudangular;} \mathrm{pc}=\mathrm{processus}$ condyloides; $\mathrm{pd}$ = pseudodentary; $\mathrm{pi}$ = processus internus; $\mathrm{pm}=$ premaxilla; $\mathrm{pt}$ = pterygoid; $\mathrm{q}=$ quadrate; $r=$ retroarticular process of the pseudoangular; $\mathrm{s}=$ stapes; $\mathrm{sc}$ = sagittal crest; $\mathrm{sm}$ = septomaxilla; $\mathrm{sn}$ = squamosal nothch; $\mathrm{sq}=\mathrm{squamosal} ; \mathrm{t}$ = foramen for tentacular ducts; $v$ = vomer.

Although not identical, numbers of teeth determined from CT scans are reassuringly similar to direct counts.

Tongue with more or less longitudinal plicae over entire surface, margin free not covering any inner mandibular teeth, sides forming an angle of c. $100^{\circ}$ anteriorly. Choanae elongate, much longer than wide, distance between them more than eight times their maximal transverse diameters, posterior limit about level with middle of the eye. Palate without plicae.

First groove in the collar region (interpreted as first nuchal groove) poorly marked on dorsum and dorsolaterally, not visible in ventral view. Second nuchal 


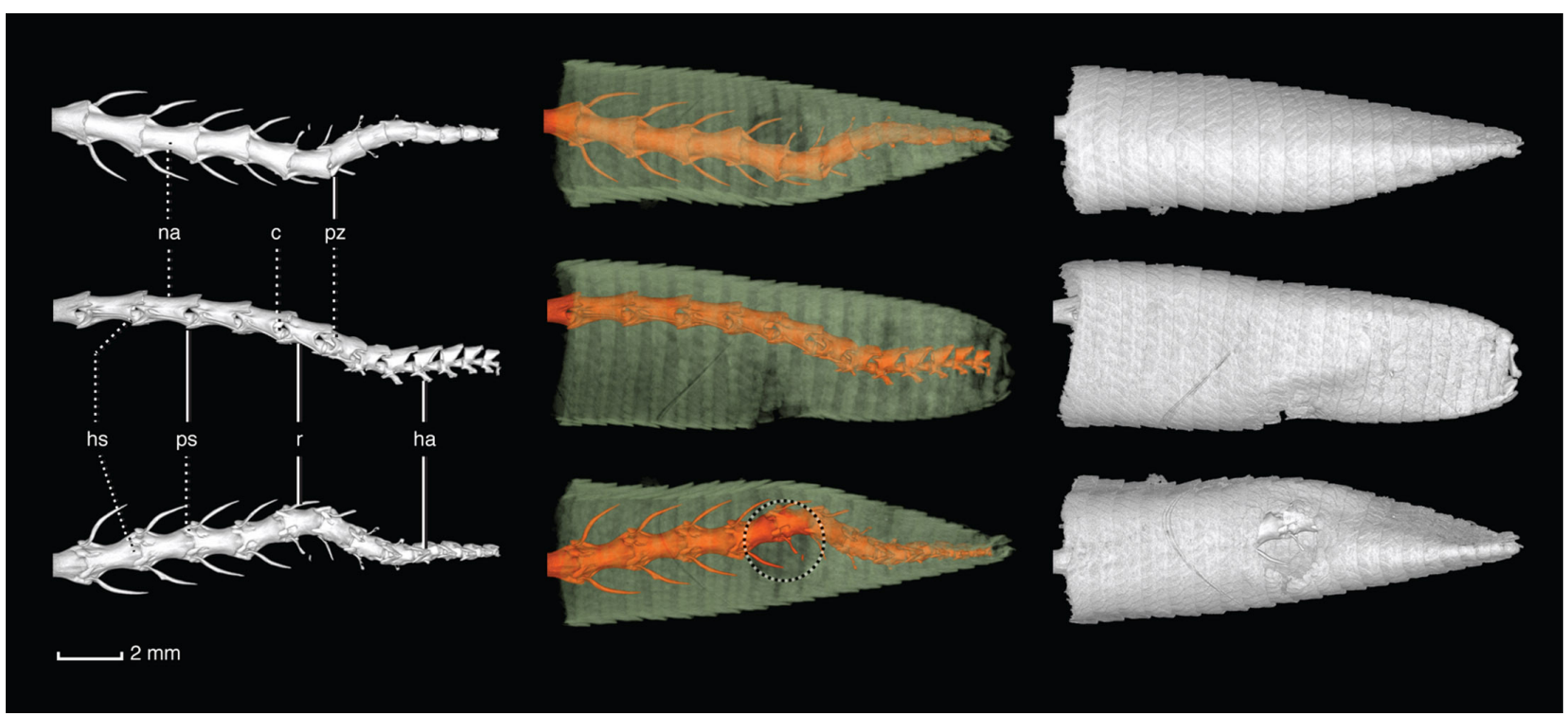

Figure 4. CT scan of tail end of USNM 320729, holotype of Amazops amazops sp. nov. revealing vertebrae (left), scales (right) and relationship between scales (green) and vertebrae (orange), in dorsal (top) lateral (middle) and ventral (bottom) views. C = centrum; ha = haemal arch; hs = hyposphene; na = neural arch; $p s$ = parasphene; $p z$ = prezygapophysis; $r$ = rib. Dotted circle highlights the scale free region surrounding the vent.

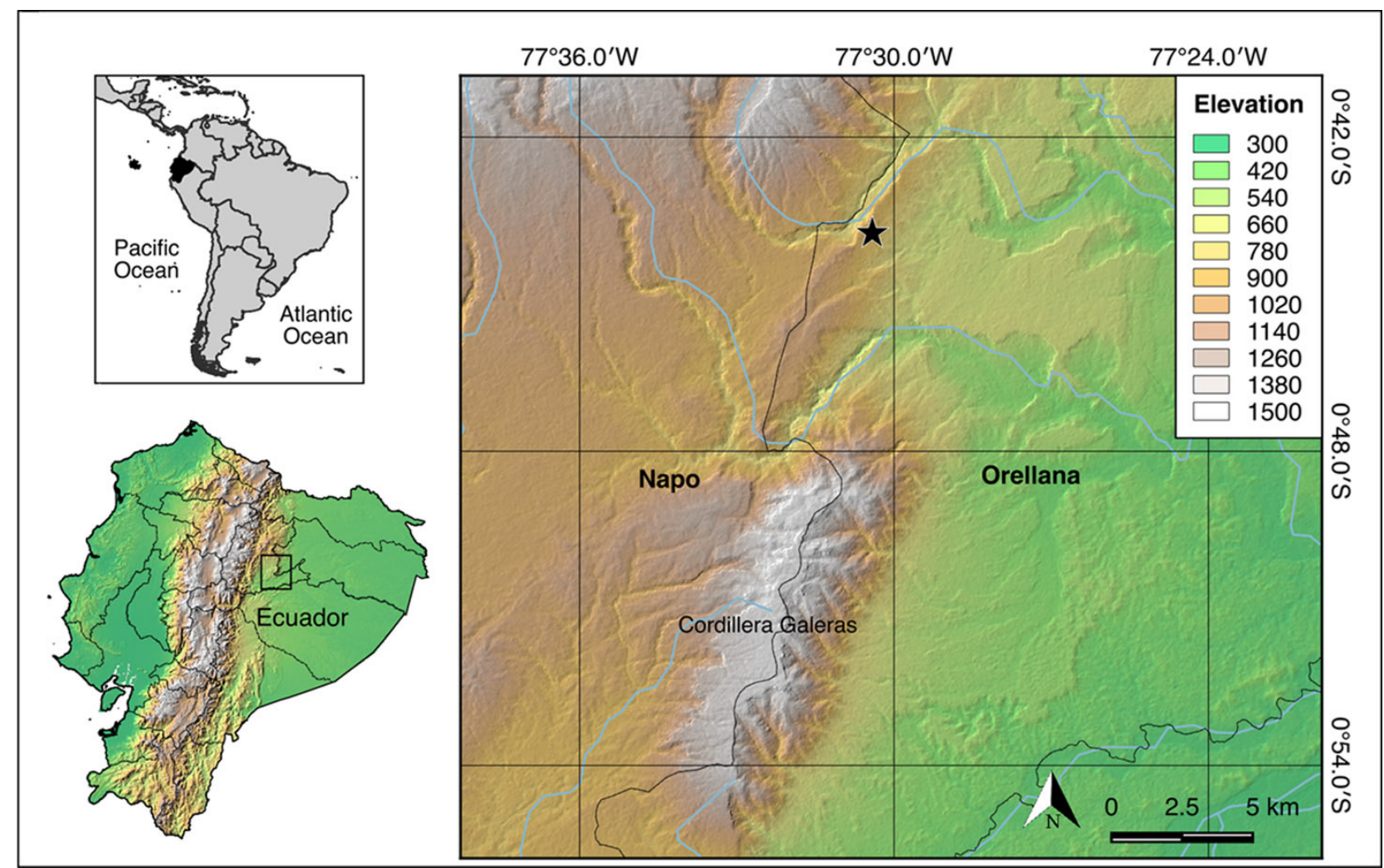

Figure 5. Map showing type locality (black star) of Amazops amazops sp. nov.

groove faint dorsally, pale and clearly marked laterally and ventrally. Third nuchal groove complete, bows slightly anteromedially on the dorsum and resembles subsequent annular grooves. First nuchal collar much shorter (1.2 $\mathrm{mm}$ ) than the second $(4.5 \mathrm{~mm})$. Four regularly spaced dorsal transverse grooves on second collar bowing slightly anteromedially and of slightly increasing length all ending dorsolaterally. Behind the collars 247 annular grooves, those in the first third and last sixth orthoplicate, otherwise slightly angulate (curving posteromedially) on venter except last complete annular groove before the vent which curves anteromedially mirroring the anterior limit of the disc. First and last (c. 15-20) annuli are a little longer than others. Annular grooves are complete ventrally except for two interrupted by the vent and disc, tail (area behind the vent) with ten complete and one 
(the last) dorsoventrally incomplete annular grooves.

A single row of small subcircular scales present in shallow pockets (about one quarter the length of a midbody annulus) below the dorsal transverse grooves on the second nuchal collar. At midbody and posteriorly, scales occur in two well-defined rows, a posterior row of larger scales (e.g., $1.1 \times 1.0 \mathrm{~mm}$ ) and an anterior row of slightly smaller scales, in pockets about as deep as the length of an annulus at midbody, about one and a half times the length of an annulus posteriorly. Additional scattered scales may lie below (posterior to) the row of larger scales. The two rows of scales in posterior annuli can be clearly discerned in the CT scan of the tail end (Fig. 4), which reveals that apart from the last rows, scales mostly form complete transverse rings around the body and tail except where these and the associated annuli are interrupted by the vent. Scales in a single row overlap with their neighbours. Midventral scales are superficial to the proximal edges of the adjacent scales on each side, the distal edges of which are superficial to the proximal edges of the succeeding adjacent scale and so on until some mid-dorsal scale with edges that are deep to both its neighbours. Successive scale rows are offset in a brick layout (i.e., shifted half a scale in the transverse direction).

Vent slightly longitudinal, bordered by an irregular array of partially subdivided denticulations, perhaps two pairs and one posteromedial denticulations posteriorly, posterior denticulations pigmented and glandular like the adjacent skin especially peripherally, anterior denticulations, pale, with shorter interdenticular grooves. There is no disc other than what is delimited by the denticulations around the vent, approximately eggshaped with the narrow apex anterior formed by the unpigmented denticulations. No indication of papillae. Very small ovarian eggs (largest c. $0.8 \mathrm{~mm}$ diameter) are visible towards the front of the ventral incision. There are no melanophores in the viscera.

Almost uniformly dark, brownish lavender, slightly paler on the head, more so on throat. Pale areas around eye, a slightly paler snout tip encompassing nares. Pale, narrow, faint paramandibular stripes (inset from lips) on ventral surface of head, distinctive pale second nuchal groove on ventral collar region. Paler around vent, especially anteriorly. Annular grooves with a light posterior margin and typically slightly longer anterior dark, aglandular area.

Other than the osteological features that distinguish Amazops amazops sp. nov. from the species of Rhinatrema and Epicrionops, the skull and mandibles are typically rhinatrematid (Nussbaum, 1977). Thus they are zygokrotaphic, with the characteristic squamosal notch and associated process of the os basale and medial parietal ridges providing part of the origin of the primary adductor musculature. There are separate septomaxillae but prefrontals and postfrontals are lacking. The os basale forms a continuous bony dorsal margin of the foramen magnum and a well-developed parasphenoidal rostrum separates the vomers. The retroarticular processes of the mandibles are relatively short and straight, not curving medially or dorsally. Different from what has been reported for other rhinatrematids (Nussbaum, 1977; Reiss, 1996), the pterygoids are large and single on each side with posterodorsal processes closely adpressed to the quadrates and there is no indication of any pterygoid process of the quadrate. There are 77 vertebrae of which the last seven are entirely posterior to the vent and differ from more anterior vertebrae in bearing some indication of haemal arches associated with the parasphenes. Bony ribs are absent from the last four of these caudal vertebrae.

Remarks. That the species is known from a single specimen is sufficient reason to suggest that the IUCN conservation status of the species should be data deficient. Effort is needed to identify populations of this distinctive lineage as a precursor to any meaningful study of its natural history. Based on it being a rhinatrematid it is assumed that it will share the reproductive mode of the other rhinatrematids, as far as is known, in being oviparous with an aquatic larval stage (San Mauro et al., 2014, Müller, 2020) and thus being dependent on water bodies for its reproduction.

Etymology. As for the genus. For nomenclatural purposes the specific epithet is considered to be a genderless noun in apposition.

\section{DISCUSSION}

Wilkinson et al. (2011) provided a minimalistic most recent diagnosis of the Rhinatrematidae as the only caecilians with the primary adductor musculature originating dorsomedially and passing through the upper temporal fenestrae, a feature discovered by Nussbaum (1977) and argued to provide evidence for Rhinatrematidae being the sister group of all other caecilians. Although not observed directly in Amazops, osteological correlates of this condition (the substantial upper temporal fenestra and a sagittal crest mid-dorsally on the parietals) are apparent from CT scans. Also apparent is the squamosal notch receiving a process of the os basale that Nussbaum (1977) identified as a synapomorphy of the family. Nussbaum's (1977) original diagnosis of the Rhinatrematidae, and the subsequent diagnoses of Nussbaum \& Wilkinson (1989) and Wilkinson \& Nussbaum (2006), also included three osteological features (fronto-squamosal contact, quadrate-maxillopalatine contact laterally, and orbit entirely within the maxillopalatine) that do not pertain in Amazops. As well as setting Amazops apart from other rhinatrematids, these differences would need to be taken into account in any less minimalistic rediagnosis of the family.

Nussbaum (1977:16) noted that "the quadrate articulates with the maxillary portion of the maxillopalatine in Epicrionops and Rhinatrema, a condition which is apparently unique to these two genera among living vertebrates and is, therefore, an important diagnostic feature of the Rhinatrematidae". Nussbaum (1977) considered this to be an ancestral condition within caecilians based on comparison with labryinthodonts, though one might reasonably doubt that assessment given that labyrinthodonts typically have 
a jugal separating the quadrate and maxilla and because no such contact is reported in a putative stem caecilian (Jenkins et al., 2007). The lack of contact between the maxillopalatine and quadrate along the ventrolateral margin of the cranium in the type of Amazops might perhaps reflect incomplete maturity of that specimen. This articulation is not present in larvae but develops at metamorphosis (Reiss, 1996) and the notch-like gap between the elements is small and would represent an unusual feature in a mature animal. On the other hand similar sized representatives of other species including the slightly smaller type of Epicrionops colombianus have extensive contact between the squamosal and maxillopalatine, there are no other traces of larval features in the holotype that would suggest incomplete metamorphosis, and other metamorphic fusions (of the maxillae and palatines) or expansions (of the squamosals) are not incomplete. Thus the condition of Amazops is seemingly unique among metamorphosed rhinatrematids and it remains plausible though quite uncertain that this is an ancestral character state within the family and evidence that Amazops as the sister of the other rhinatrematids.

Amazops differs from other rhinatrematids in having more elongate squamosals occupying areas anteriorly that are occupied by the maxillopalatine in other rhinatrematids, and contributing to the bony orbits and making contact with the frontals at the anterior ends of the upper temporal fenestrae. Comparisons with fossils are of limited utility in determining character polarity because the various conditions within Rhinatrematidae and within the extant Gymnophiona as a whole all appear derived with respect to the fossil and living outgroups. That these features do not occur elsewhere within rhinatrematids suggest they might be derived conditions under the criterion of common equals primitive (Estabrook, 1977). However, these features are common (nearly universal) in non-rhinatrematid caecilians, implying either convergence with these or that they are instead ancestral for Gymnophiona. The latter implies that Amazops represents one side of the basal divergence within known rhinatrematids and is the sister taxon to all other known rhinatrematids. Other characters do not seem to preclude that possibility. Reiss (1996) reported that the pterygoids divide into two at metamorphosis in Epicrionops and considered that to be a derived condition, implying that the undivided pterygoids of Amazops represent an ancestral condition within caecilians.

Given that caecilian taxonomy can be challenging because of the paucity of external characters and of specimens (Wilkinson, 2020), non-destructive CT scanning may be particularly helpful for revealing details of character systems that would remain otherwise undetermined. Externally, Amazops is very similar to Epicrionops and, in the absence of the knowledge of its cranial morphology provided by CT scanning, would probably have been described as a species of that genus. Traditional examination of caecilian scales is limited by the necessity of opening scale pockets and the difficulty of visualising scale rows within the scale pockets, but
CT scanning can also provide very helpful visualisation of scales in situ. Similarly, counting teeth may be easier, more accurate, and more informative (by yielding separate counts for each tooth bearing element, rather than composite counts for multi element series) from CT scans.

After Taylor's (1968) monographic revision of caecilian taxonomy, there was a hiatus of more than 40 years before the description of any new species of rhinatrematid caecilians. That hiatus was ended by the relatively rapid descriptions of four new species of Rhinatrema from the Guianas and lowland Amazonian Brazil (Gower et al., 2010; Wilkinson \& Gower, 2010; Maciel et al., 2018). In contrast, the majority of described rhinatrematid species are from the Andes and description here of a new Andean rhinatrematid is the first such for over 50 years. This highlights how incompletely known and poorly surveyed are the rhinatrematid caecilians of the Andes and the possibility that there may be many undescribed species awaiting discovery.

\section{ACKNOWLEDGEMENTS}

We thank the following individuals and their institutions for assistance in facilitating loans or other access to type specimens of rhinatrematid caecilians in their care: Alain Dubois, Ivan Ineich and Annemarie Ohler (Museum National d'Histoire Naturelle, Paris); the late Jens Rassmusen (Zoological Museum, University of Copenhagen); Darrel Frost (American Museum of Natural History); Steve W. Gotte and Robert Wilson (United States National Museum of Natural History, Smithsonian Institution); Miguel Trefaut Rodrigues, Hussam Zaher and the late Paulo Vanzolini (Museu de Zoologia, Univesidade de São Paulo); the late Georges Lenglet (Royal Belgian Institute of Natural Sciences), Roger Pérez-Hernández (Museo de Biologia Univesdade Central Venezuela, Caracas). Gabriela Bittencourt provided a careful review and substantial help in preparing figures. Steve Gotte helped determine coordinates for the type locality. Thanks also to Hendrik Müller, Ramachandran Kotharambath and Simon Maddock for careful and insightful reviews. MW's visit to the Smithsonian in 2016 during which our collaboration was initiated was supported in part by funding from the Natural History Museum, London. RPR would like to thank Jay M. Savage for examining the Holotype and confirming that it represented an undescribed species. William W. Lamar accompanied RPR and JFJ in the field and provided the photograph of the specimen in life. We wish to thank Dr. Sergio Figueroa for issuing Ecuador scientific specimen collecting permit No. 049 dated 14 August 1990, Dr. Napoleon Carvajal for issuing Ecuador scientific specimen export permit No. 231 dated 7 September 1990, and Sr. Ramiro Estrella for issuing CITES permit 059 IC dated 7 October 1990.

\section{REFERENCES}

Estabrook, G.F. (1977). Does common equal primitive? Systematic Botany 2, 36-42.

Gower, D.J., Wilkinson, M., Sherratt, E. \& Kok, P.J. (2010) A 
new species of Rhinatrema Duméril \& Bibron (Amphibia: Gymnophiona: Rhinatrematidae) from Guyana. Zootaxa 2391, 47-60. DOI: 10.11646/zootaxa.2391.1.3

Jenkins Jr, F.A., Walsh, D.M. \& Carroll, R.L. (2007) Anatomy of Eocaecilia micropodia, a limbed caecilian of the Early Jurassic. Bulletin of the Museum of Comparative Zoology 158, 285-365. DOI: 10.3099/0027-4100(2007)158[285:AO EMAL]2.0.CO;2

Maciel, A.O., Sampaio, M.I., Hoogmoed, M.S. \& Schneider, H. (2018). Description of two new species of Rhinatrema (Amphibia: Gymnophiona) from Brazil and the return of Epicrionops niger to Rhinatrema. South American Journal of Herpetology 13,287-299. DOI: 10.2994/SAJH-D-17-00054.1

Müller, H. (2020) Development and demography of larval Epicrionops bicolor (Amphibia: Gymnophiona: Rhinatrematidae), Neotropical Biodiversity 6, 98-108. DOI: 10.1080/23766808.2020.1756131]

Nussbaum, R.A. (1977) Rhinatrematidae: A new family of caecilians (Amphibia: Gymnophiona). Occasional Papers of the Museum of Zoology, University of Michigan 682, 1-30.

Nussbaum, R.A. \& Wilkinson, M. (1989) On the classification and phylogeny of caecilians (Amphibia: Gymnophiona), a critical review. Herpetological Monographs 3, 1-42.

Reiss, J. (1996). Palatal metamorphosis in basal caecilians (Amphibia: Gymnophiona) as evidence for lissamphibian monophyly. Journal of Herpetology 30, 27-39.

San Mauro, D., Gower, D.J., Müller, H., Loader, S.P., Zardoya, R., Nussbaum, R.A. \& Wilkinson, M. (2014) Life-history evolution and mitogenomic phylogeny of caecilian amphibians. Molecular Phylogenetics and Evolution 73, 177-189. DOI: 10.1016/j.ympev.2014.01.009

Taylor, E.H. (1968) The Caecilians of the World: a Taxonomic Review. Lawrence: University of Kansas Press. 848 p.

Wilkinson, M. (1996) The heart and aortic arches of rhinatrematid caecilians (Amphibia: Gymnophiona).
Zoological Journal of the Linnean Society 118, 135-150.

Wilkinson, M. (2020) Taxonomic status of the enigmatic Guyanese endemic caecilian Caecilia pressula Taylor, 1968 (Amphibia: Gymnophiona: Caeciliidae). Herpetological Journal 30, 227-229.

Wilkinson, M. \& Gower, D.J. (2010) A new species of Rhinatrema Duméril \& Bibron (Amphibia: Gymnophiona: Rhinatrematidae) from Amazonas, Brazil. Zootaxa 2650, 63-68. DOI: 10.11646/zootaxa.2650.1.6

Wilkinson, M., Malonza, P.K., Campbell, P. \& Loader, S.P. (2017) A new species of Boulengerula Tornier, 1896 (Amphibia: Gymnophiona: Herpelidae) from Kenya and the "rediscovery" of Boulengerula denhardti. Zootaxa 4286, 525-534. DOI: 10.11646/zootaxa.4286.4.5

Wilkinson, M. \& Nussbaum, R.A. (1996) On the phylogenetic position of the Uraeotyphlidae (Amphibia: Gymnophiona). Copeia 1996, 550-562.

Wilkinson, M. \& Nussbaum, R.A. (2006) Caecilian phylogeny and classification. Pp. 39-78 in (J.-M. Exbrayat, ed.) Reproductive Biology and Phylogeny of Gymnophiona (caecilians). Science Publishers, Inc., Enfield, New Hampshire, U.S.A.

Wilkinson, M., Presswell, B., Sherratt, E., Papadopolou, A. \& Gower, D.J. (2014) A new species of striped Ichthyophis Fitzinger, 1826 (Amphibia: Gymnophiona: Ichthyophiidae) from Myanmar. Zoootaxa 3785, 45-58. DOI: 10.11646/ zootaxa.3785.1.4

Wilkinson, M., San Mauro, D., Sherratt, E. \& Gower D.J. (2011). A nine-family classification of caecilians (Amphibia: Gymnophiona). Zootaxa 2874, 41-64.

Wilkinson, M., Sherratt, E., Starace, F. \& Gower, D.J. (2013) A new species of skin- feeding caecilian and the first report of reproductive mode in Microcaecilia (Amphibia: Gymnophiona: Siphonopidae). PLOS ONE 8(3), e57756. DOI: 10.1371/journal.pone.0057756

Accepted: 14 October 2020 